\title{
Frequency and Predictors of Radial Artery Occlusion after Coronary Procedure through Transradial Approach: A Vascular Doppler-guided Study
}

\author{
Mohammad Abdul Matin1, Mir Jamal Uddin², Abdul Momen³, Mustafizul Aziz ${ }^{3}$, Abeeda Tasnim Reza4, \\ Fathima Aayesha Cader ${ }^{4}$, Ashraf-Ur Rahman ${ }^{4}$, Forhad Karim Majumder ${ }^{4}$, \\ A B M Riaz Kawsar ${ }^{5}$, Shubra Chakraborty ${ }^{5}$.
}

\begin{abstract}
:
Background: Although transradial approach (TRA) has better outcome and reduced vascular complications, radial artery occlusion (RAO) is now a major concern as it limits future radial artery use for further TRA, for use as a conduit during CABG, for invasive hemodynamic monitoring and for creation of arteriovenous fistula for hemodialysis in CKD patients. Vascular doppler study is the most accurate method for evaluation of RAO and yet this is not practiced in our population. Objectives: To detect the frequency and identify the predictors of RAO after coronary procedure through TRA. Methods: This cross-sectional analytical study was done in the department of cardiology, NICVD from July-2015 to June2016 by including a total 125 patients undergoing coronary procedures (CAG and/or PCI) through TRA. Vascular doppler study of the radial artery were performed before and one day after the procedure. RAO was defined as an absence of antegrade flow and monophasic flow on doppler study. Univariate and multivariate logistic regression analysis were done to evaluate the predictors of RAO. Results: On the day after the
\end{abstract}

procedure, radial artery vascular doppler examination revealed RAO in $12(09.6 \%)$ patients. On univariate analysis female gender $(p=0.038)$, diabetes mellitus $(p=0.024)$, prolonged hemostatic compression for more than 02 hours after sheath removal $(p=0.003)$ were identified as predictors of RAO. Interestingly hypertension, low BMI, smaller radial artery diameter and use of reprocessed sheath were not identified as predictors of RAO. On multivariate analysis diabetes mellitus $(p=0.016)$, prolonged hemostatic compression for more than 02 hours after sheath removal $(p=0.004)$ were found as independent predictors for RAO. Conclusion: Frequency of RAO was $09.6 \%$ after coronary procedure through TRA. Diabetes mellitus and hemostatic compression after sheath removal for more than two hours were identified as independent predictors of RAO. Strategies should be taken from patient selection for TRA to end of hemostatic compression removal to prevent RAO.

Keywords: Radial artery occlusion, Transradial approach, Coronary procedure.
Introduction:

Cardiovascular diseases account for more than 17 million deaths globally each year contributing $30 \%$ of all

1. Junior consultant (Cardiology), Upazila Health complex, Parshuram, Feni

2. Professor of Cardiology, NICVD, Dhaka.

3. Associate Professor of Cardiology, NICVD, Dhaka.

4. Postgraduate fellow, Department of Cardiology, NICVD, Dhaka.

5. Medical officer, Department of Cardiology, NICVD, Dhaka.

Address of Correspondence: Dr Mohammad Abdul Matin, Junior consultant (Cardiology), UHC, Parshuram, Feni. Flat: 2C, House: 266-

2/A, Ishakha Road, Ahmednagar, Paikpara, Mirpur-1, Dhaka-1216.

Mobile 01818407794, E-mail: rdrmatin@gmail.com. deaths. $80 \%$ of those occur in low-income and middleincome countries. Coronary artery disease (CAD) alone caused 07 million deaths worldwide in $2010^{1}$. Coronary angiogram (CAG) is the gold standard method for the diagnosis and for establishing treatment strategies. CAG can be performed via femoral, radial and ulnar arteries. Till now the most common access site is transfemoral approach (TFA) for any interventional procedure. However, vascular access site complications such as bleeding, hematoma, arteriovenous fistula and pseudoaneurysm

DOI: https://doi.org/10.3329/bhj.v34i2.44441

Copyright (C 2017 Bangladesh Cardiac Society. Published by Bangladesh Cardiac Society. This is an Open Access articles published under the Creative Commons Attribution-NonCommercial 4.0 International License (CC BY-NC). This license permits use, distribution and reproduction in any medium, provided the original work is properly cited and is not used for commercial purposes. 
are quite common after procedures through TFA ${ }^{2}$. The reduction of ischemic events and complications after $\mathrm{PCl}$ has increased the focus on non-ischemic complications particularly vascular access site complications ${ }^{3}$. Due to less vascular complications TRA for coronary procedure is gaining momentum as an alternative to the TFA. But TRA is technically more challenging than TFA and it requires longer learning curve. Through the TRA the first CAG was performed by Lucian Campeau in $1989^{4}$ and the first $\mathrm{PCl}$ was performed in 1992 by Ferdinand Kiemeneij ${ }^{5}$.

Worldwide an estimated $22 \%$ procedures are performed by this route ${ }^{6}$. The radial artery has become the preferred choice due to its easy compressibility, distance from major veins and nerves, and accompanying blood flow through the ulnar artery to the palmar arch. This approach is preferred by both patient and physician, because this approach results in improved time to ambulation, additional comfort to patients, shorter hospitalization duration, lower hospital expenses, reduces potentially life-threatening complications and improve clinical outcomes 7,8 . TRA is an attractive options for same-day or outpatient procedure, with the data supporting its safety, efficacy and potential financial savings. That's why In the STEMI-RADIAL trial, the radial and femoral approaches were compared in patients with STEMI and radial access was associated with an $80 \%$ reduction in the incidence of complications at the puncture site and local bleeding ${ }^{9}$. Considering these results, the ESC Guidelines of management of STEMI ${ }^{10}$ and NSTE-ACS ${ }^{11}$ has given priority to TRA over TFA. Beside of these advantages TRA has some additional transradial specific vascular complications, such as spasm, radial artery perforation, compartment syndrome and radial artery occlusion (RAO) ${ }^{6}$.

Radial artery occlusion (RAO) appears to be a silent enemy after radial artery catheterization. RAO is mostly asymptomatic but can cause serious complication like hand ischemia ${ }^{12}$. The incidence of this complication evaluated shortly after the procedure varies widely in the literature, ranging from $2 \%$ to $18 \%{ }^{13}$. RAO can be evaluated by radial pulse method, Barbeau's test (plethysmographic evidence) and vascular doppler study. In a study by Huang et al, ${ }^{14}$ showed the rate of immediate occlusion was $4.7 \%$ by radial pulse method (absent pulse), and $10.7 \%$ by vascular doppler study.

RAO depends on a number of demographic, clinical and periprocedural factors. Low body weight ${ }^{15}$, female gender ${ }^{16}$, use and dose of anticoagulant ${ }^{17}$, the diameter of the radial artery, sheath size, the number of catheters, procedure duration, type and duration of access site compression after the procedure are some of the factors associated with $\mathrm{RAO}^{18,19}$. Recently in India in a study by Garg et al, ${ }^{20}$ showed lower BMI, diabetes mellitus, preprocedural radial artery diameter d" $2.5 \mathrm{~mm}$, low preprocedural peak systolic velocity and radial artery to sheath ratio $<1$ were the additional predictors of RAO. Kim et al, ${ }^{21}$ described a direct pathophysiological factor of RAO is a thrombus which is due to damage to the endothelium, arterial smooth muscle contraction and slow-flow/no-flow of the blood stream creating a favorable environment for the formation of thrombi. The material aspirated from the artery in histopathological evaluation proved to be a thrombus ${ }^{13}$. The use of reprocessed sheaths can cause microstructural physical changes which predisposes to thrombosis. By understanding the patho-physiological mechanism and growing appreciation of the importance of the problem, a reduction in the incidence of RAO has been observed. This is due to recognition and implementation of effective prevention methods ${ }^{22}$.

As only presence of palpable radial artery is not sufficient to exclude RAO, this study was undertaken to detect the frequency and to identify the predictors of RAO in patients undergoing coronary procedure through TRA by vascular color doppler study.

\section{Methods:}

This cross-sectional, analytical study was conducted in department of cardiology, National Institute of Cardiovascular Diseases (NICVD), Dhaka, Bangladesh from July 2015 to June 2016. All patients undergoing CAG and/or PCl through transradial approach in NICVD during the specified period of time were considered for the study. Total 125 patients were studied after selecting by purposive non-random sampling method. Patients with age more than 18 years undergoing coronary procedure with positive Allen's test and normal radial arterial blood flow by vascular doppler study were included and patient with negative Allen's test, prior CABG surgery using radial artery, history of radial and/or ulnar artery injury and having arterio-venous fistula or planned for making arterio-venous fistula were excluded from this study. Meticulous history was taken, detailed clinical examination was performed. Pre-procedural vascular doppler assessment of radial artery was done. Procedural characteristics were recorded during the procedure. After the procedure patients were followed for 24 hours, than post-procedural vascular doppler assessment of radial artery was done for detection of radial artery occlusion (RAO). After detection of RAO, patients were grouped in two groups: without RAO (groupI) and with RAO (group-II). Analysis was done for identification of predictors of RAO. The Statistical Package for Social Sciences (SPSS) version 19 software was used for data analysis. Continuous variables were expressed as mean and standard deviation and compared through the unpaired t-test. Categorical variables were expressed as absolute number and percentages and were compared through the Pearson's chi-square test and Fisher's exact test. Univariate and multivariate logistic 
regression analysis was done to identify the predictors of RAO. P-value of less than 0.05 was considered statistically significant.

Ethical issue: The study protocol was approved by the ethical review committee of NICVD. Informed written consent was taken from each patient or near relatives. Confidentiality was maintained strictly and the patient had the right to withdraw himself/herself from the study at any time during the study period. Data was collected in an approved data collection form.

\section{Results:}

Among 125 patients with coronary artery disease undergoing coronary procedures through TRA were studied by vascular color doppler study for development of RAO after TRA. $113(90.4 \%)$ patients did not develop RAO after TRA and belonged to group-I and 12 (09.6\%) patients developed RAO after TRA and belonged to groupII. Mean age of study population was $50.47 \pm 9.38$ and $49.67 \pm 8.96$ years in respectively in group I \& II. Male patients were predominant $(84.1 \%$ vs $58.3 \%)$ in both groups. Hypertension was the commonest risk factor of CAD in both groups ( $41.6 \%$ vs $66.7 \%$ ) followed by smoking (38.1\% vs $41.7 \%$ ) and diabetes mellitus (31.9\% vs $66.7 \%)$. Mean pre-procedural radial artery diameter was $2.51 \pm 0.33$ vs $2.40 \pm 0.25 \mathrm{~mm}$ in group I and group-II. Mean preprocedural peak systolic velocity of radial artery was $52.6 \pm 019.5$ vs $41.1 \pm 12.9 \mathrm{~cm} / \mathrm{sec}$ in group I and group-II.

In univariate analysis shows female gender (OR, 3.770; $\mathrm{Cl}, 1.076-13.202 ; p=0.038)$, diabetes mellitus (OR, 4.278; $\mathrm{Cl}$, 1.209-15.138; $p=0.024)$, and hemostatic compression time more than 02 hours (OR, 37.333; Cl, 3.515-396.252; $p=0.003$ ), were found to be significant predictors of postprocedural radial artery occlusion (RAO). On multivariate logistic regression analysis shows diabetes mellitus (OR, 7.348; Cl, 1.460-36.989; $p=0.016)$, hemostatic compression time more than 02 hours (OR, 63.076; Cl, 3.890-1022.636; $p=0.004$ ), were independent predictors of post-procedural radial artery occlusion (RAO).

Table-III demonstrates comparison of the procedural and post-procedural characteristics. Reprocessed sheath was used in 66(58.4\%) and $08(66.7 \%)$ patients respectively in group I and group II. Hemostasis was done by conventional haemostatic method in 102 (90.3\%) patients in group I but in all patients in group II. Majority of the patients were also given haemostatic compression for 02 hours or less time $(99.1 \%$ in group-I and $75 \%$ in group-II).

Univariate logistic regression analysis shows female gender, diabetes mellitus and hemostatic compression

Table I

Frequency of study population according to radial artery occlusion $(n=125)$

\begin{tabular}{lcc}
\hline Study populations & Number & $\%$ \\
\hline Without radial artery occlusion (group-I) & 113 & 90.4 \\
With radial artery occlusion (group-II) & 12 & 09.6 \\
\hline Total & 125 & 100 \\
\hline
\end{tabular}

Table-II

Demographic and clinical characteristics of study population $(n=125)$

\begin{tabular}{|c|c|c|}
\hline Demographic and clinical characteristics & Group I $(n=113)$ & Group II $(n=12)$ \\
\hline Age in years (Mean \pm SD) & $50.47 \pm 9.38$ & $49.67 \pm 8.96$ \\
\hline \multicolumn{3}{|l|}{ Gender, n (\%) } \\
\hline Male & $95(84.1)$ & $07(58.3)$ \\
\hline Female & $18(15.9)$ & $05(41.7)$ \\
\hline Smoking & $43(38.1)$ & $05(41.7)$ \\
\hline Hypertension & $47(41.6)$ & $08(66.7)$ \\
\hline Diabetes mellitus & $36(31.9)$ & $08(66.7)$ \\
\hline Dyslipidaemia & $43(38.1)$ & $06(50.0)$ \\
\hline Family history of CAD & $39(34.5)$ & $43(38.1)$ \\
\hline BMI (Mean \pm SD) & $24.54 \pm 3.09$ & $24.63 \pm 3.87$ \\
\hline \multicolumn{3}{|l|}{ Clinical diagnosis, n (\%) } \\
\hline STEMI & $23(20.3)$ & $2(16.7)$ \\
\hline NSTEMI & $25(22.1)$ & $3(25)$ \\
\hline UA & $38(33.6)$ & $4(33.3)$ \\
\hline CSA & $27(23.9)$ & $3(25)$ \\
\hline Preprocedural radial artery diameter in $\mathrm{mm}$ (Mean \pm SD) & $2.51 \pm 0.33$ & $2.40 \pm 0.25$ \\
\hline Preprocedural peak systolic velocity (Mean \pm SD) & $52.6 \pm 19.5$ & $41.1 \pm 12.9$ \\
\hline
\end{tabular}


Table-III

Procedural and postprocedural characteristics of study population $(n=125)$

\begin{tabular}{|c|c|c|c|c|}
\hline \multirow{2}{*}{$\begin{array}{l}\text { Procedural and postprocedural } \\
\text { characteristics }\end{array}$} & \multicolumn{2}{|c|}{ Group I $(n=113)$} & \multicolumn{2}{|c|}{ Group II $(n=12)$} \\
\hline & Number & $\%$ & Number & $\%$ \\
\hline \multicolumn{5}{|l|}{ Types of procedure } \\
\hline CAG & 59 & 52.2 & 08 & 66.7 \\
\hline $\mathrm{PCl}$ & 54 & 47.8 & 04 & 33.3 \\
\hline \multicolumn{5}{|l|}{ Types of sheath used } \\
\hline New & 47 & 41.6 & 04 & 33.3 \\
\hline Reprocessed & 66 & 58.4 & 08 & 66.7 \\
\hline \multicolumn{5}{|l|}{ Types of haemostatic method } \\
\hline Conventional method & 102 & 90.3 & 12 & 100 \\
\hline Patent haemostatic method & & 09.7 & 00 & 00 \\
\hline \multicolumn{5}{|l|}{ Haemostatic compression time } \\
\hline 02 hours or less & 112 & 99.1 & 09 & 75.0 \\
\hline More than 02 hours & 01 & 0.91 & 03 & 25.0 \\
\hline
\end{tabular}

Group-I: Study population without RAO, Group-II: Study population with RAO

Table-IV

Univariate logistic regression analysis of predictors of radial artery occlusion $(n=125)$

\begin{tabular}{lccc}
\hline Variable & Odds Ratio & $95 \% \mathrm{Cl}$ & $\mathrm{p}$ value \\
\hline Female gender & 3.770 & $1.076-13.202$ & $0.038^{\mathrm{s}}$ \\
Hypertension & 2.809 & $0.799-09.873$ & $0.107^{\mathrm{ns}}$ \\
Diabetes mellitus & 4.278 & $1.209-15.138$ & $0.024^{\mathrm{s}}$ \\
$\mathrm{BMI}\left(\mathrm{kg} / \mathrm{m}^{2}\right)$ & 1.009 & $0.837-1.217$ & $0.924^{\mathrm{ns}}$ \\
Preprocedural radial artery diameter $<02 \mathrm{~mm}$ & 0.438 & $0.112-1.704$ & $0.233^{\mathrm{ns}}$ \\
Use of reprocessed sheath & 1.424 & $0.405-5.007$ & $0.581^{\mathrm{ns}}$ \\
Procedure time & 0.972 & $0.936-1.008$ & $0.128^{\mathrm{ns}}$ \\
Hemostatic compression time $>02$ hours & 37.333 & $3.515-396.252$ & $0.003^{\mathrm{s}}$ \\
\hline
\end{tabular}

$\mathrm{Cl}=$ Confidence interval, $\mathrm{ns}=$ Not significant $(\mathrm{p}>0.05), \mathrm{s}=$ Significant $(\mathrm{p}$ d"0.05)

Table-V

Multivariate logistic regression analysis of predictors of radial artery occlusion $(n=125)$

\begin{tabular}{lccc}
\hline Variable & Odds Ratio & $95 \% \mathrm{Cl}$ & $\mathrm{p} \mathrm{value}$ \\
\hline Female gender & 1.853 & $0.405-8.473$ & $0.426^{\mathrm{ns}}$ \\
Diabetes mellitus & 7.348 & $1.460-36.989$ & $0.016^{\mathrm{s}}$ \\
Hemostatic compression time $>02$ hours & 63.076 & $3.890-1022.636$ & $0.004^{\mathrm{s}}$ \\
\hline
\end{tabular}

$\mathrm{Cl}=$ Confidence interval, $\mathrm{ns}=$ Not significant $(p>0.05), \quad s=$ Significant $(p$ d"0.05)

time more than two hours were found to be significant predictors of postprocedural radial artery occlusion (RAO).

Multivariate logistic regression analysis shows diabetes mellitus, hemostatic compression time more than two hours were independent predictors of post-procedural radial artery occlusion (RAO).

\section{Discussion:}

In this study, comparable with previous studies, TRA has high procedural success, low complication rates, and presents a low economic burden in experienced hands in the diagnosis and treatment of CAD. Failure of puncture of the radial artery, spasmodic or anatomical barriers 
such as radial arterial loop, and failure of coronary artery engagement are the most common causes of procedural failure via TRA ${ }^{23}$. In a study conducted by Dehghani et $\mathrm{al}^{24}$ the causes of procedural failure via TRA were radial arterial spasm, subclavian tortuosity, inadequate catheter support, failure of radial artery canulation, radial arterial dissection and radial arterial loop. In our study, one patient had radial artery loop and another patient had subclavian artery loop but those were successfully passed. Several studies demonstrated that with increasing operator experience, radial procedural failure dropped below $5 \%{ }^{24}$.

One of the significant complication of TRA is RAO, the incidence of which is very much variable from study to study. However, in some studies using doppler, the incidence of RAO is higher than only using absent pulse as a criterion of RAO. Sa' et al, ${ }^{25}$ conducting a study on Brazil found incidence of early RAO (within 07 days) was $10.5 \%$. Another vascular doppler guided study in India conducted on patients undergoing transradial coronary angioplasty found that RAO was $15.2 \%$ one day after the procedure ${ }^{20}$. Results of our study in which RAO was determined by vascular doppler study showed that frequency of RAO were $09.6 \%$ which is less than the previous studies.

In our study, mean radial artery diameter was found 2.49 $\pm 0.32 \mathrm{~mm}$ (range, 1.87 to 3.22 ). Our finding is in accordance with the previous studies done in other Asian country populations $\left(2.6 \pm 0.3 \mathrm{~mm}\right.$ in Korea ${ }^{26}$ and $2.5 \pm$ $0.4 \mathrm{~mm}$ in Japan ${ }^{27}$. In our study, mean radial artery diameter was $2.40 \pm 0.25 \mathrm{~mm}$ in patients who had developed RAO. In our study, five patients with radial artery diameter $<2 \mathrm{~mm}$ (mean $1.94 \pm 0.05 \mathrm{~mm}$ ) were undergone coronary procedures with $6 \mathrm{~F}$ catheter (radial artery to sheath ratio <1). RAO rate was $20 \%$ in patients with radial artery to sheath ratio $<1$ as compared to $9.8 \%$ if the ratio was e"1. This finding has importance, as Saito et al, ${ }^{28}$ demonstrated that a radial artery diameter/sheathdiameter ratio $<1$ is associated with a reduction in distal flow. Larger sized sheaths have been increased chance of development of RAO, because of more intimal damage and favoring thrombus formation.

On univariate logistic regression analysis, in our study female gender, diabetes mellitus, hemostasis compression time more than two hours were found to be the predictors of radial artery occlusion. Garg et al, ${ }^{20}$ also found female gender, diabetes mellitus as predictors of RAO on univariate regression analysis. Females have relatively smaller average radial artery diameters, and are much more susceptible to vascular spasm and could be the reason for higher RAO in females. In our study females are also had relatively smaller radial artery diameter $(2.38 \pm 0.33 \mathrm{~mm})$ in comparison to male $(2.51 \pm$ $0.26 \mathrm{~mm}$ ); females were also had more development of spasm $04(13 \%)$ in comparison to male $05(4.9 \%)$. Deftereos et al, ${ }^{29}$ also reported that females were more prone to develop radial artery spasm. Patients with longterm diabetes mellitus have the propensity to develop arteriopathy and accelerated atherosclerosis ${ }^{30}, 31$. Another risk factor for RAO is prolonged compression of the radial artery. Tight prolonged hemostatic compression creates stasis and favorable environment for occlusive thrombus formation. Thrombus formation appears to be involved in the pathophysiology of early RAO ${ }^{18}$. However, in our study hypertension, BMI, use of reprocessed sheath, amount of heparin used, procedure duration and types of procedure (CAG or $\mathrm{PCl}$ ) were not predictor of RAO on univariate logistic regression analysis. Sa' et al, ${ }^{25}$ conducting a study on Brazil also did not find any association of RAO with use of reprocessed sheath. Heparin therapy is necessary for the prevention of RAO 27 , 32. In our study, minimum 5000 IU heparin was used during CAG and maximum 17,500 IU of heparin (according to $\mathrm{ACT}$ ) during $\mathrm{PCl}$.

Finally in multivariate logistic regression analysis, our study had shown that diabetes mellitus and prolonged hemostasis compression for more than two hours were the significant independent predictors for RAO. In a retrospective study conducted to see the effect of duration of hemostatic compression on RAO after TRA revealed incidence of RAO was $12 \%$ when hemostatic compression time is six hours after completion of the procedure and $5.5 \%$ when hemostatic compression time is two hours and prolonged occlusive compression was the independent predictor of RAO ${ }^{19}$. This finding of our study are also in accordance with the recently published meta-analysis of RAO by Rashid et al, ${ }^{33}$ as they mentioned shorter compression time in patent hemostasis setting is associated with less chance of development of RAO.

\section{Conclusion:}

This study was conducted to detect the frequency and identify the predictors of radial artery occlusion (RAO) after coronary procedures through transradial approach (TRA). Radial artery occlusion (RAO) occurred in significant number of patients (09.6\%). Diabetes mellitus and prolonged hemostatic compression time more than two hours after removal of vascular access sheath were emerged as independent predictors of RAO from this study. Strategies should be taken from patient selection 
for TRA to end of hemostatic compression removal to prevent RAO.

\section{References:}

1. Wong ND. Epidemiological studies of $\mathrm{CHD}$ and the evolution of preventive cardiology. Nat Rev Cardiol. 2014;11:276-289.

2. Choussat R, Black A, Bossi I, Fajadet J, Marco J. Vascular complications and clinical outcome after coronary angioplasty with platelet IIb/IIla receptor blockade. Comparison of transradial vs. transfemoral arterial access. Eur Heart J. 2000;21:662-667.

3. Sciahbasi A, Pristipino C, Ambrosio G, Sperduti I, Scabbia EV, Greco C, et al. Arterial access-siterelated outcomes of patients undergoing invasive coronary procedures for acute coronary syndromes (from the comparison of early invasive and conservative treatment in patients with Non-STElevation acute coronary syndromes [PRESTOACS] vascular sub study). Am J Cardiol. 2009;103:796-800.

4. Campeau L. Percutaneous radial artery approach for coronary angiography. Cathet Cardiovasc Diagn . 1989;16(1):3-7.

5. Kiemeneij F, Laarman GJ, Melker E. Transradial coronary artery angioplasty. Am Heart J. 1995;129(1):1-7.

6. Caputo RP, Tremmel JA, Rao S, Gilchrist IC, Pyne C, Pancholy S, et al. Core Curriculum; Transradial Arterial Access for Coronary and Peripheral Procedures: Executive Summary by the Transradial Committee of the SCAI. Catheter Cardiovasc Interv. 2011;1-17.

7. Bertrand OF, Larochelliere RD, Rodes-Cabau J, Proulx G, Gleeton O, Nguyen CM, et al. A randomized study comparing same-day home discharge and abciximab bolus only to overnight hospitalization and abciximab bolus and infusion after transradial coronary stent implantation. Circulation, 2006;114 (24):2636-2643.

8. Roussanov O, Wilson SJ, Henley K, Estacio G, Hill $\mathrm{J}$, Dogan $\mathrm{B}$, et al. Cost-effectiveness of the radial versus femoral artery approach to diagnostic cardiac catheterization. J Invasive Cardiol. 2007;19(8): 349-353.

9. Bernat I, Horak D, Stasek J, Mates M, Pesek J, Ostadal P, et al. ST-Segment elevation myocardial infarction treated by radial or femoral approach in a multicenter randomized clinical trial, The STEMIRADIAL Trial. J Am Coll Cardiol. 2014;63(10): 964-972.

10. Steg PG, James SK, Atar D, Badano LP, BlömstromLundqvist C, Borger MA, et al. ESC Guidelines for the management of acute myocardial infarction in patients presenting with ST-segment elevation. Task Force on the management of ST-segment elevation acute myocardial infarction of the European Society of Cardiology (ESC). Eur Heart J. 2012;33:2569-2619.

11. Hamm WC, Bassand JP, Agewall S, Bax J., Boersma E, Bueno H, et al. ESC Guidelines for the management of acute coronary syndromes in patients presenting without persistent ST-segment elevation. The Task Force for the management of acute coronary syndromes (ACS) in patients presenting without persistent ST-segment elevation of the European Society of Cardiology (ESC). Eur Heart J. 2011;32:2999-3054

12. Rademakers LM, Laarman, GJ. Critical hand ischaemia after transradial cardiac catheterisation: an uncommon complication of a common pro-cedure. Neth Heart J. 2012;20:372-375.

13. Pancholy SB. Transradial access in an occluded radial artery: New technique. J Invasive Cardiol. 2007;19:541-544.

14. Huang $\mathrm{CH}$, Chen $\mathrm{CY}$, Chen IC. Impact of the tansradial approach to coronary angiography or angioplasty on radial artery in Taiwanese population. Acta Cardiol Sin. 2004;20:212-218.

15. Plante S, Cantor WJ, Goldman L, Miner S, Quesnelle A, Ganapathy A, et al. Comparison of bivalirudin versus heparin on radial artery occlusion after transradial catheterization. Cath-eter Cardiovasc Interv. 2010;76:654-658.

16. Tunçez A, Kaya Z, Aras D, Yildiz A, Gul EE, Tekinalp $M$, et al. Incidence and predictors of radial ar-tery occlusion associated transradial catheterization. Int J Med Sci. 2013;10(12):1715-1719.

17. Spaulding $C$, Lefevre T, Funck F, Thebault B, Chauveau M, Hamda, KB, et al. Left radial approach for coronary angiography: results of a prospective study. Cathet Cardiovasc Diagn. 1996;39(4): 365-370.

18. Pancholy S, Coppola J, Patel T. Roke-Thomas M. Prevention of radial artery occlusion-patent 
hemostasis evaluation trial (PROPHET study): a randomized comparison of traditional versus patency documented hemostasis after transradial catheterization. Catheter Cardiovasc Interv. 2008;72:335-340.

19. Pancholy SB, Patel TM. Effect of duration of hemostatic compression on radial artery occlusion after transradial access. Catheter Cardiovasc Interv. 2012;79:78-81.

20. Garg N, Madan BK, Khanna R, Sinha A, Kapoor A, Tewari $S$, et al. Incidence and predictors of radial artery occlusion after transradial coronary angioplasty: Doppler-guided follow-up study. J Invasive Cardiol. 2015;27:106-112.

21. Kim KS, Park HS, Jang WI, Park JH. Thrombotic occlusion of the radial artery as a complication of the transradial coronary intervention'. J Cardiovasc Ultrasound. 2010;18(1):31.

22. Hamon M, Pristipino C, Di-Mario C, Nolan J, Ludwig $\mathrm{J}$, Tubaro $\mathrm{M}$, Consensus document on the radial approach in percutaneous cardiovascular interventions: position paper by the European Association of Percutaneous Cardiovascular Interventions and Working Groups on Acute Cardiac Care and Thrombosis of the European Society of Cardiology'. Eurolntervention, 2013;8:1242-1251.

23. Varenne O, Jégou A, Cohen R, Empana JP, Salengro $\mathrm{E}$, Ohanessian A, et al. Prevention of arterial spasm during percutaneous coronary interventions through radial artery: The SPASM study. Catheter Cardiovasc Interv 2006;68:231-235.

24. Dehghani P, Mohammad A, Bajaj R, Hong T, Suen $\mathrm{CM}$, Sharieff W, et al. Mechanism and predictors of failed transradial approach for percutaneous coronary interventions. JACC Cardiovasc Interv. 2009;2(11):1057-1064.

25. Sá BJL, Barros LFT, Bandao SCS, Victor EG. Interference of Reprocessed Introducers in Radial Artery Occlusion after Cardiac Catheterization. Rev Bras Cardiol Invasiva. 2013;21(3):270-275.
26. Yoo BS, Lee SH, Ko JY, Lee BK, Kim SN, Lee MO. Procedural outcomes of repeated transradial coronary procedure. Catheter Cardiovasc Interv. 2003;58(3):301-304.

27. Nagai S, Abe S, Sato T, Hozawa K, Yuki K, Hanashima K, et al. Ultrasonic assessment of vascular complications in coronary angiography and angioplasty after transradial approach'. Am J Cardiol. 1999;83:180-186.

28. Saito S, Ikei H, Hosokawa G, Tanaka S. Influence of the ratio between radial artery inner diameter and sheath outer diameter on radial artery flow after transradial coronary intervention. Catheter Cardiovasc Interv. 1999;46:173-178.

29. Deftereos S, Giannopoulos G, Kossyvakis C, Driva M, Kaoukis A, Raisakis K, et al. Radial artery flowmediated dilation predicts arterial spasm during transradial coronary interventions. Catheter Cardiovasc Interv. 2011;77(5):649-654.

30. Ruengsakulrach P, Sinclair R, Komeda M, Raman J, Gordon I, Buxton B. Comparative histopathology of radial artery versus internal thoracic artery and risk factors for development of intimal hyperplasia and atherosclerosis. Circulation, 1999;100(19 Suppl):139-144.

31. Chowdhery UK, Airan B, Mishra PK, Kothari SS, Subramaniam GK, Ray R, et al. Histopathology and morphometry of radial artery conduits: basic study and clinical application. Ann Thorac Surg. 2004;78(5):1614-1621.

32. Sanmartin M, Gomez M, Rumoroso JR, Sadaba M, Martinez M, Baz JA, et al. Interruption of blood flow during compression and radial artery occlusion after transradial catheterization. Catheter Cardiovasc Interv. 2007;70:185-189.

33. Rashid M, Pancholy S, Chugh S, Kedev SA, Bernat I, Ratib K, et al. Radial artery occlusion after transradial interventions: A systematic review and meta-analysis. J Am Heart Assoc. 2016;5:e002686. 